\title{
Pensar local e agir global: Práticas de preservação do rio Mamanguape e a Educação Ambiental no Ensino Fundamental.
}

\section{Think Local and Act Global: Mamanguape River Preservation Practices and Environmental Education in Elementary School.}

Jacinta Antonia Duarte Ribeiro Rodrigues

Universidade Estadual da Paraíba, Campina Grande, Paraíba (Brasil) duartejacinta545@gmail.com

Maria Elaine Almeida do Nascimento

Universidade Estadual da Paraíba, Campina Grande, Paraíba (Brasil) elaine.pedagogia.ufpb@gmail.com

Fecha recepción: 12/09/2019

Páginas 34-48

Fecha aceptación: 25/12/2019

\section{Resumo.}

A Educação Ambiental é um tema muito discutido atualmente, e diante desse contexto, pensamos em inserir esta temática na escola, para promover a reflexão, a observação e a discussão dessa temática, a fim de levar os alunos a se relacionarem com o meio ambiente sem agredi-lo. Nesta perspectiva, o presente estudo objetivou analisar a compreensão, a relação e as observações dos alunos sobre os desafios para a Educação Ambiental na Escola Joaquim Clementino da Silva Freire a partir da necessidade de preservação do Rio Mamanguape do município de Alagoa GrandePB. Como metodologia, o mesmo se baseou na pesquisa bibliográfica, que favoreceu a construção do arcabouço teórico e compreensão do tema investigado, e na pesquisaação do tipo exploratória, que norteou a investigação da prática em campo. Como instrumento de coleta de dados foi utilizado um questionário, e a interpretação dos dados obtidos foram avaliados na perspectiva da abordagem quali-quantitativa. 0 público participante desse estudo foi composto por alunos do $4^{\circ}$ e $5^{\circ}$ ano da escola supracitada. A pesquisa obteve resultados positivos em relação aos objetivos almejados, revelando, e deixando mais compreensível e urgente para nós, a necessidade da inserção da temática sobre os cuidados com o Meio Ambiente no espaço escolar.

Palavras-chave: meio ambiente; educação ambiental; preservação; rio mamanguape; ensino fundamental

\section{Abstract.}

Environmental Education is a topic much discussed today, and considering this context, we think of inserting this theme in school, to promote reflection, observation and discussion of this theme, in order to lead students to relate to the environment without beat him up. In this perspective, the present study aimed to analyze students' 
understanding, relationship and observations about the challenges for Environmental Education at Joaquim Clementino da Silva Freire School from the need to preserve the Mamanguape River in the city of Alagoa Grande-PB. As a methodology, it was based on the bibliographic research, which favored the construction of the theoretical framework and understanding of the investigated theme, and the exploratory action research, which guided the investigation of the practice in the field. As a data collection instrument, a questionnaire was used and the interpretation of the obtained data were evaluated from the perspective of the qualitative and quantitative approach. The public participating in this study was composed of students from the 4th and 5th grade of the above school. The research obtained positive results in relation to the desired objectives, revealing, and making it more understandable and urgent for us, the need to insert the theme about environmental care in the school space.

Keywords: environment; environmental education; preservation; mamanguape river; elementary school

\section{1.-Introdução.}

Os pátios escolares e as salas de aula a cada término de expediente apresentam um cenário bastante interessante para pensarmos a sensibilização para o meio ambiente. Geralmente os alunos jogam papel de bombons, chicletes, folhas de caderno amassadas, caixas de sucos e garrafinhas de plástico no chão, numa justificativa aceita por todos: de que as auxiliares de serviço se encarregarão da limpeza. Podemos também acrescentar o local onde ficam os bebedouros e banheiros que, em sua maioria, apresentam uma grande quantidade de desperdício de água com contínuos vazamentos e torneiras ligadas interruptamente sem ninguém usá-las durante todo 0 dia.

Dessa forma, a escola é um bom termômetro para identificarmos a distância entre os conteúdos ensinados sobre meio ambiente e as práticas fora da sala de aula. Em sua maioria, a discussão na escola não tem sido suficiente para provocar no alunado sensibilização e nem os induzir para as mudanças, novas visões e novas posturas em relação ao meio ambiente, não correspondendo a sugestão de Marcatto (2002) que considera a transformação de atitudes como uma das características da Educação Ambiental.

Sendo assim, se nossas crianças, adolescentes e jovens não conseguirem contribuir para a limpeza e usos do lixo num espaço de menor escala que é o seu ambiente escolar, como irão se posicionar diante das questões ambientais mais complexas da sua rua, do seu bairro, cidade, país ou planeta? Deveras, há uma urgência de efetivar uma Educação Ambiental que possibilite uma intervenção para além dos conteúdos e informações, mas, que se desdobre em novos valores e consciência ecológica.

Por tanto, pretendemos nesta pesquisa analisar a compreensão, a relação e as observações dos alunos sobre os desafios para a Educação Ambiental na Escola Municipal Joaquim Clementino da Silva Freire, a partir da necessidade de preservação do Rio Mamanguape do município de Alagoa Grande-PB.

Nesse contexto, achamos pertinente pensar sobre as relações da Educação Ambiental e o Rio Mamanguape, uma vez que a escola foi construída às suas margens e nesse 
sentido, parte da comunidade escolar (professores, alunos e funcionários), em sua maioria, também são moradores próximos.

Alguns questionamentos podem nos ajudar a refletir melhor sobre a temática escolhida, uma vez que há uma necessidade constante de pensarmos nos problemas reais e as relações da humanidade com o meio em que vive, a fim de garantir não somente a vida no planeta, mas, a capacidade de intervir e participar nas soluções e processos que envolvem cidadania, desde uma pequena escola até mesmo numa escala planetária, ou seja, em outras palavras, "pensar global e agir local".

Dessa forma, o nosso trabalho estará direcionado para os alunos tendo como 0 princípio à sensibilização, colaboração e participação ativa de ações que podem minimizar as ações antrópicas geradas por toda comunidade escolar, incluindo a população que reside próximo ao rio Mamanguape e que poderá contribuir para os futuros profissionais que, por ventura, venham atuar nesta área ou aqueles que já atuam e desejam sempre conhecer as experiências vivenciadas por sua categoria.

\section{2.- A questão ambiental e sua relação com as práticas de aprendizagem.}

De acordo com as nossas pesquisas, constatamos que a Educação Ambiental no Brasil passou por vários acontecimentos, podemos citar um descrito por Alves (2007, p. 23), ocorrido em 1972 em Estocolmo, na Suécia, caracterizada como Conferência sobre 0 Ambiente Humano, com recomendações aos 113 países participantes, inclusive o Brasil, surgindo assim, a criação do Programa Internacional de Educação Ambiental (PIEA), que foi reconhecido como um caminho para se chegar a uma solução para o combate a crise ambiental mundial.

Porém, foi no ano de 1981 que a Educação Ambiental foi instituída no Brasil de maneira formal pela Lei 6.938, sendo necessária a criação de uma Política Nacional de Meio Ambiente (PNMA), voltada para oferecer a Educação Ambiental nas escolas de todo estado brasileiro em todos os níveis de ensino. Assim, a Educação Ambiental, como perspectiva educativa, pode estar presente em todas as disciplinas. Sem impor limites para seus estudantes, tem caráter de educação permanente. Ela, por si só, não resolverá os complexos problemas ambientais planetários, mas pode influir decididamente para isso, ao formar cidadãos conscientes de seus direitos e deveres. (Reigota, 2001, p. 62)

Diante deste contexto, podemos citar também o surgimento dos PCNs no ano de 1997, trazendo em seu volume 8 a apresentação dos Temas Transversais e Ética, abordando dentre outros assuntos o Meio Ambiente, onde nos leva a refletir que "o ser humano faz parte do meio ambiente e as relações sociais, econômicas e culturais também fazem parte desse meio e, portanto, são objetos da área ambiental." (MEC, 2004, p.33)

Vale ressaltar, que o documento supracitado foi direcionado para os anos iniciais do Ensino Fundamental e muito tem contribuído para nortear a prática do professor em sala de aula. Sabemos que a questão ambiental vem sendo considerada cada vez mais urgente e importante para a sociedade, pois o futuro da humanidade depende da relação estabelecida entre a natureza e o uso pelo homem dos recursos naturais disponíveis. 
Relatos, fotos e pesquisas são divulgados diariamente sobre problemas que afetam 0 Meio Ambiente, nos quais a natureza mostra sinal de esgotamento que nos últimos anos tem se refletido no próprio homem, seu principal agressor.

Portanto, trabalhar esta temática em sala de aula, se faz necessário pelo fato de que a escola é um espaço viável para contribuir com estratégias que busquem soluções para amenizar a crise ambiental, pois, é importante que o professor trabalhe com 0 objetivo de desenvolver, nos alunos, uma postura crítica diante da realidade, de informações e valores veiculados pela mídia e daqueles trazidos de casa. Para tanto, 0 professor precisa conhecer 0 assunto e, em geral, buscar junto com seus alunos mais informações em publicações ou com especialistas (PCNs, 1997, p. 25).

De acordo com os PCNs (1997, p.35), isso não quer dizer que os professores deverão "saber tudo" para que possam desenvolver um trabalho junto aos alunos, mas estejam motivados a aprender e se aperfeiçoar pela temática, embora este seja um processo inacabado. Entendemos assim, que a formação continuada deve fazer parte da vida dos docentes para atualização de informações e construção de conhecimentos, pois como diz Alves (2007, p. 40) "a formação do professor é a condição essencial para que as questões relacionadas às práticas da educação ambiental sejam inseridas no ensino formal".

Sendo assim, mediante está problemática, percebemos que a degradação ambiental é um sério problema que acomete todo o planeta, dentre eles o lixo, a escassez de água, o desmatamento, o aquecimento global, entre outros, os quais nos deparamos todos os dias com situações desastrosas inseridas neste contexto.

Sendo assim, de acordo com o Manual de Educação para o Consumo Sustentável (2005, p.16) "o ambiente natural está sofrendo uma exploração excessiva que ameaça a estabilidade dos seus sistemas de sustentação (exaustão de recursos naturais renováveis, desfiguração do solo, perdas de florestas, poluição da água e do ar, perda de biodiversidade, mudanças climáticas, etc.)". Portanto, pensar em Educação Ambiental, é pensar em mudança de hábitos e atitudes, é estar disposto a abrir mão da vaidade e do egoísmo para consumir apenas o necessário, e a apropriação desta decisão surge a partir dos nossos valores, pois quando os valores mostrarem que é tão importante o "ter" quanto o "ser" e 0 "fazer", repensaremos nossas atitudes e passaremos a consumir apenas o necessário. Então, a ética e 0 respeito ao meio ambiente, serão a chave para economizar os recursos naturais, salvar o planeta e garantir a continuidade da vida na Terra. (Calvi, 2010, p. 38)

Explorar os termos relacionados à questão ambiental, através das aulas de Educação Ambiental, é uma oportunidade de sensibilizar os educandos para desenvolver neles hábitos simples como fechar a torneira ao se ensaboar, não jogar lixo no chão e, consequentemente, levá-los para uma visão mais ampla de conservação ambiental, através de exposição de problemas e possíveis soluções, construindo no alunado um perfil de um cidadão consciente e comprometido com as causas ambientais.

Portanto, Rosa (2001, p.5) afirma "que a sensibilização é um elemento e/ou instrumento da Educação Ambiental, usados na mobilização dos educandos para se atingir mudança de comportamento e desenvolver uma consciência crítica capaz de entender melhor problemas ambientais."

É importante dizer que não existem receitas prontas para o professor desenvolver estas competências e habilidades nos alunos, mas repensar as metodologias e buscar 
aperfeiçoá-las, contextualizando-as com a realidade de cada discente, já é um bom caminho.

\section{1.-Caracterizando o Rio Mamanguape.}

Um desafio à sustentabilidade está em preservar os nossos mananciais, principalmente aquele que será o objeto de estudo do nosso trabalho, ou seja, o Rio Mamanguape.

O Rio Mamanguape nasce na região entre o Brejo e 0 Cariri paraibano, em uma lagoa temporária, denominada de Salgada, localizada no Planalto da Borborema a 500 metros de altitude. De cima da serra, o rio segue com seu leito escavado em profundo vale, escoando até a cidade de Alagoa Grande.

Após $35 \mathrm{~km}$ de percurso o rio Mamanguape alcança níveis altimétricos inferiores aos 200 metros, atravessando o boqueirão de Alagoa Grande entre as serras Paquevira e do Boi.

Figura 1 - Mapa do Rio Mamanguape

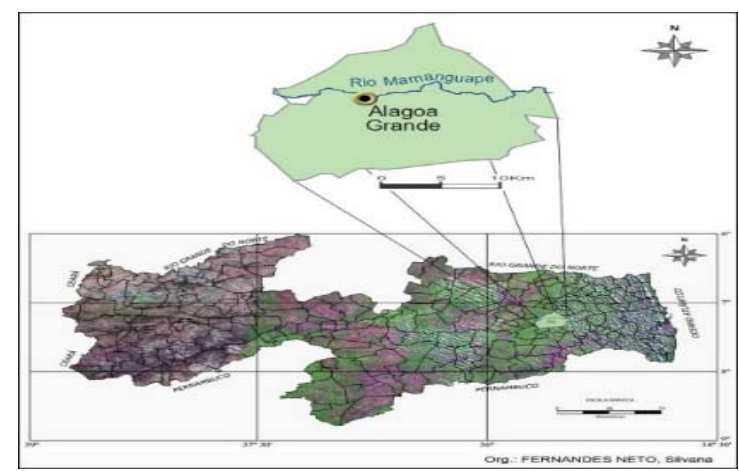

Fuente própria.

No alto curso ele é temporário, ou seja, seca nas estações de seca, apesar das contribuições dos riachos perenes do Brejo. A junção de dois ou três regatos alarga 0 vale do Brejo, permitindo a instalação de engenhos.

Durante as estiagens, as águas do rio se infiltram no leito arenoso ou evaporam, e o leito se transforma num areal onde a água subterrânea aflora em poços. De março a julho as águas correm no rio, havendo cheias em junho e julho. (Projeto aguas - S/A). A vegetação primitiva no Brejo era a mata tropical de altitude, com espécies de zona costeira. A floresta foi destruída, permanecendo poucas manchas remanescentes, que atualmente podem ser observadas na região de Matinhas. No alto curso, o rio Mamanguape nasce na divisa dos municípios de Pocinhos, Areal e Montadas, caracterizando-se como divisor dos municípios de Lagoa de Roça, Lagoa Seca, Matinhas e Alagoa Nova, chegando a Alagoa Grande. Dentre os lugares do alto curso do rio Mamanguape iremos destacar a cidade de Alagoa Grande, por ser foco principal de nosso estudo. 


\section{3.-Caracterização da Escola e da comunidade escolar.}

A pesquisa se desenvolveu na Escola Joaquim Clementino da Silva Freire nas turmas do $4^{\circ}$ e $5^{\circ}$ ano do Ensino Fundamental, com 40 crianças e as 2 professoras das turmas, respectivamente. A escola se localiza às margens do Rio Mamanguape, onde 0 acesso é dado através de um portão principal do muro externo, depois seguido de uma pequena passagem e novamente um segundo portão para a entrada no corredor principal da escola.

Figura 2 - Localização da escola nas proximidades do rio Mamanguape.

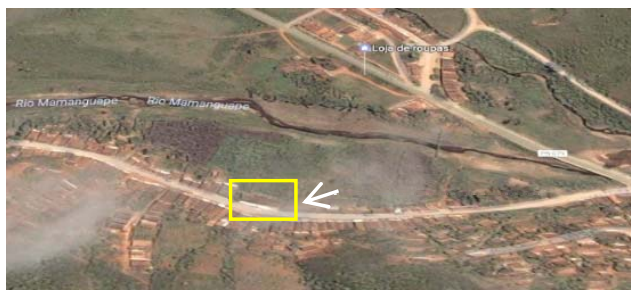

Fonte: google/maps

A título de modalidades de ensino a escola oferece apenas os anos iniciais do Ensino Fundamental ( $1^{\circ}$ ao $5^{\circ}$ ano). Em relação a sua infraestrutura, a escola possui serviço de água e energia da rede pública, bem como lixo destinado à coleta periódica.

Matricula Inicial: Fonte Secretaria da Escola Municipal Joaquim Clementino TABELA 1 - QUADRO DE MATRÍCULA DE ALUNOS

\begin{tabular}{c|c|c}
\hline SÉRIE & $\mathbf{N}^{0}$. TURMAS & $\mathbf{N}^{0}$. ALUNOS \\
\hline $1^{0}$ ano & 01 & 45 \\
\hline $2^{0}$ ano & 01 & 29 \\
\hline $3^{0}$ ano & 01 & 31 \\
\hline $4^{0}$ ano & 01 & 25 \\
\hline $5^{0}$ ano & 01 & 18 \\
\hline Total & & 148
\end{tabular}

Fonte própria.

A escola tem uma boa infraestrutura, mas necessitando de acabamento e reformas, com quatro salas de aula e dois banheiros. No entanto, a escola não possui biblioteca, cozinha, laboratório de informática, sala de leitura, quadra de esportes, sala para a diretoria, sala para os professores, sala de atendimento especial. Os equipamentos de que dispõe a escola são aparelho de DVD, televisão, computador e impressora, no entanto, não possui internet nem banda larga, nem tão pouco computadores disponíveis para os alunos e professores.

A construção das salas de aula em concreto não favorece muito a ventilação nem a iluminação, pois, mesmo durante o turno diurno as salas de aulas ficam com as 
lâmpadas acesas o que corrobora com o aumento do calor provocado durante as aulas.

Há necessidade também de melhor conforto nas cadeiras onde os alunos permanecem a maior parte do tempo, encontramos salas de aula com cadeiras com assento de madeira ou de plásticos com sustentação de ferro, os quais não contribuem muito para a permanência de muito tempo sentados.

A escola também não possui lugares adequados para os momentos de recreação, 0 que deduzimos que o espaço que fica entre o muro e a escola é melhor local escolhido pelos alunos, uma vez que tem luz e ventilação natural, mas não há espaço para brincadeiras nem bancos ou cadeiras para sentar, os alunos se acomodam nos batentes e nos corredores. Além disso, a falta de um refeitório, lugar específico para a alimentação, é um fator preocupante, pois os alunos se alimentam nas mesmas condições descritas acima.

Os alunos são apontados, constantemente, como inquietos e suas famílias não demonstram tanta responsabilidade sobre eles. Percebemos que as crianças são ativas, porém a ludicidade ainda não é realizada com tanto afinco, devido a falta de espaços adequados, tanto na sala de aula como na área da escola.

\section{3.-Metodologia.}

Para embasamento e arcabouço teórico, o presente estudo se utilizou da pesquisa bibliográfica, uma vez que a mesma [...] é uma pesquisa cujos dados e informações são coletados em obras já existentes e servem de base para análise e interpretação dos mesmos, formando um novo trabalho científico. (Severino, 2007, p. 47).

Para a aplicação em campo, utilizamos a metodologia da pesquisa-ação do tipo exploratória, considerando que a pesquisa-ação, de acordo com Severino (2007), se configura como mediadora entre a teoria e a prática, problematizando a realidade e traçando alternativas para intervir na mesma, sendo ela, "um tipo de pesquisa centrada no agir" (p.70). Além disso, é exploratória à medida que promove o levantamento de informações sobre determinado objeto e mapeia condições de exploração desse objeto.

Por esse ponto de vista, nossa pesquisa foi direcionada para um público-alvo composto por 40 alunos do $4^{\circ}$ e $5^{\circ}$ ano do turno da tarde, pertencentes à Escola Municipal Joaquim Clementino da Silva Freire, situada em Alagoa Grande, interior da Paraíba. A pesquisa elencou como tema a ser explorado, a Educação Ambiental e 0 Rio Mamanguape, no que concernem as questões ambientais e seu estudo em sala de aula. Em campo, foi utilizado como ferramenta de pesquisa o uso de questionário semiestruturado impresso, o qual foi distribuído para os alunos responderem em momento da aula cedido pelo professor regente e liberado pela gestão escolar. Os dados obtidos foram avaliados do ponto de vista quali-quantitativo, os quais trataremos no tópico dos resultados e discussões.

\section{4.-Resultados e Discussão.}

A pesquisa em questão teve como público alvo 40 alunos do $4^{\circ}$ e $5^{\circ}$ ano de uma escola municipal, sendo realizada através da aplicação de questionário semiestruturado 
composto por 9 questões sobre problema ambiental, educação ambiental e 0 rio Mamanguape. Após a análise dessas etapas, discutiremos sobre o resultado desta aplicação como também acerca dos resultados obtidos.

Inicialmente conversamos com o professor regente sobre o tema que iria ser abordado, ao passo que informamos que seriam necessários vinte minutos para aplicação do questionário, o qual foi elaborado com perguntas objetivas e subjetivas. 0 tempo estipulado foi considerado curto para não comprometer o planejamento diário. Assim, nas respectivas salas de aula, exploramos:

Grafico 1: Questão 1 : Você já ouviu falar sobre problema ambiental?

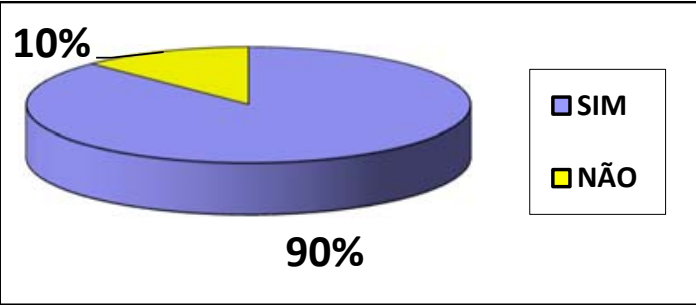

Fonte própria.

A questão inicial foi para buscar nesses alunos através do "Sim" ou do "Não", o conhecimento de cada um sobre questões relacionadas à degradação ambiental, 0 que de antemão deduzimos que seria algo comum à todos, pelo menos saberem ou já terem ouvido falar sobre isto. Porém, observamos que 10\% (04 alunos) afirmaram não conhecerem nada a respeito de problema ambiental, sendo possível perceber que mesmo a maioria, equivalente a 90\% (36 alunos), dos entrevistados demonstrarem conhecimento sobre tal questionamento, existem ainda alunos que precisam se inteirar desta temática tão presente no nosso meio.

Dos alunos que afirmaram que já tinham ouvido falar sobre problemas ambientais, pedimos em seguida para que apresentassem possíveis problemas já observados no dia a dia deles. E as respostas foram as seguintes:

Questão 2: Cite um problema ambiental que possa estar ocorrendo próximo a escola.

\begin{tabular}{|l|l|}
$\begin{array}{l}\text { IDENTIFICAÇÃO } \\
18 \text { alunos }\end{array}$ alunos & $\begin{array}{l}\text { RESPOSTA DOS ALUNOS } \\
\text { "O lixo e o esgoto" } \\
\text { "Destruição do Rio Mamanguape em } \\
\text { virtude do lixo." } \\
\text { "Os esgotos a céu aberto que tem seu } \\
\text { destino dentro do rio." } \\
4 \text { alunos } \\
\text { Fonte própria }\end{array}$
\end{tabular}

A partir das respostas observamos que, entre as questões citadas, foram mencionados os principais problemas que causam a exteriorização das margens do rio Mamanguape e, dessa forma, entendemos que há um conhecimento dos alunos em 
relação aos piores causadores de degradação deste ecossistema, quando o maior número desses estudantes citou "o lixo e o esgoto".

Neste contexto, entendemos que os próprios alunos são testemunhas dos problemas ambientais que existem tanto nas proximidades da escola, como também perto do rio, o que nos leva para a compreensão de que o saneamento básico ainda é uma carência nas cidades brasileiras, não sendo diferente no município de Alagoa Grande-PB, cidade onde ocorreu esta pesquisa. Mesmo diante da resposta de apenas cinco crianças, as quais relacionaram o problema do lixo com o rio Mamanguape, vale ressaltar que o rio acompanha toda a extensão da rua onde se localiza a escola campo da pesquisa e, dessa forma, os moradores que residem em casas mais próximas, despejam seus resíduos em suas margens, o que caracteriza um dos maiores problemas ambientais nesta localidade.

Assim, concordamos com que o lixo produzido e não coletado é disposto de maneira irregular nas ruas, em rios, córregos e terrenos vazios, e tem efeitos tais como assoreamento de rios e córregos, entupimento de bueiros com consequente aumento de enchentes nas épocas de chuva, além da destruição de áreas verdes, mau cheiro, proliferação de moscas, baratas e ratos, todos com graves consequências diretas ou indiretas para a saúde pública (Rizpah e Jacob, 2011, p. 136).

Gráfico 2: Questão 3: Qual a importância da água para a vida humana?

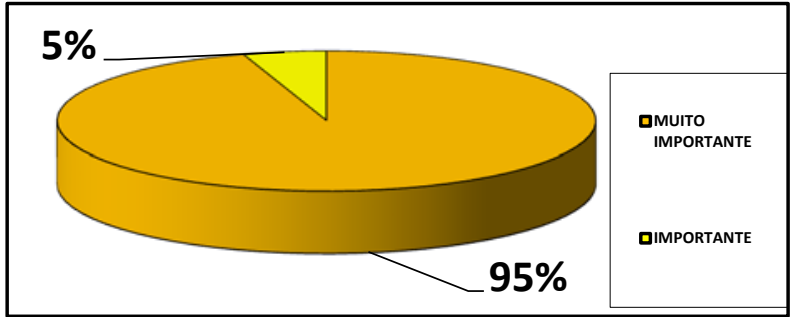

Fonte própria.

A partir desta questão, todos os alunos voltaram a participar do questionário. Como podemos observar no gráfico acima, foram colocados para os participantes duas opções de respostas. Dos 40 alunos que responderam, verificamos um resultado onde, quase por unanimidade, afirmaram a água como "muito importante" para a vida humana, computando 95\% (38 alunos). Desse total, apenas 5\% (02 alunos), mencionaram a água como "importante para a vida humana", deixando em nós uma indagação, pois como vimos anteriormente na questão 2, quando abordou-se sobre problemas ambientais, os alunos evidenciaram na questão 1 "os esgotos e 0 lixo lançados no Rio Mamanguape". Ora, sendo a água de grande importância para a vida humana, este manancial precisava estar preservado sem indícios de poluição, porém "em nosso cotidiano, é rara a oportunidade que temos para reconhecer a importância da água, tão acostumados que estamos com a sua presença e sendo ela acessível à 
grande parte da população" (CALVI, 2015, p. 4). Então, precisar e usufruir dos bens da natureza, nem sempre caracteriza cuidado e respeito por ela.

Gráfico 3: Questão 4: Como você classifica o Rio Mamanguape para a vida humana?

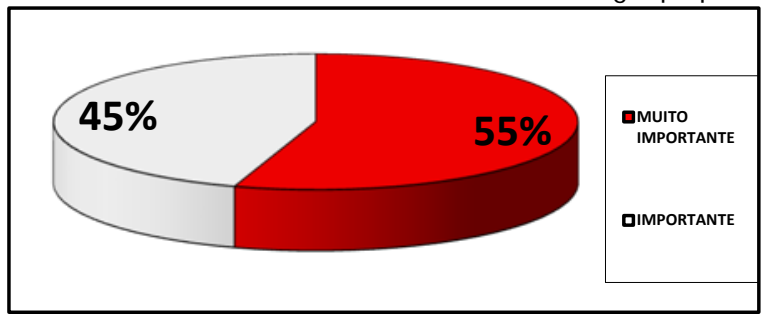

Fonte própria.

Ao fazer esta pergunta aos alunos, oferecemos para eles também duas possibilidades de resposta, conforme descrita no gráfico 3 . De certa forma, para que fosse mais coerente com a resposta anterior sobre a importância da água para a vida humana, esperávamos que a reposta "muito importante" passasse dos $90 \%$, o que não aconteceu. Ou seja, apenas $55 \%$ (22 alunos), classificaram o rio como muito importante, sendo registrado aí um distanciamento no entendimento por parte da turma como também uma incoerência em não perceber que um manancial é tão importante quanto a água.

Porém, compreendemos que há a existência de uma estiagem muito forte, deixando apenas pequenos filetes de água no rio, o que reconfigura o mesmo como fonte não necessária para a retirada e consumo da água por parte dos alunos, estes, utilizandose de outras fontes de abastecimento de água para o consumo humano, sendo esse talvez o real motivo do distanciamento de sua existência e a sua utilidade na vida das crianças.

Outra questão também, não menos importante, são os despejos dos esgotos como já mencionado, pois são responsáveis diretamente pela contaminação das águas do rio Mamanguape, tornando-as impróprias para o consumo humano.

Nas fotos abaixo é possível observar que, nesse sentido, há uma intenção direta em realizar 0 despejo dos esgotos nos rios porque 0 encanamento das residências é construído para esse fim. Não foi nossa pretensão nessa pesquisa calcular a quantidade de esgoto depositados no rio, nem atribuir culpabilidade aos alunos pelas contradições em suas respostas, mas é um fato preocupante, uma vez que encontramos essa situação em todas as casas da rua que acompanham o seu leito, ou seja, há uma quantidade significativa de esgoto sendo jogado, diariamente, no rio Mamanguape, tornando-o contaminado, sendo talvez outro motivo que impede os alunos de o reconhecerem como muito importante para a vida humana.

Foto 3 e 4 - Encanamento residencial para depósito de esgotos nas margens do rio Mamanguape. Fonte: acervo pessoal 

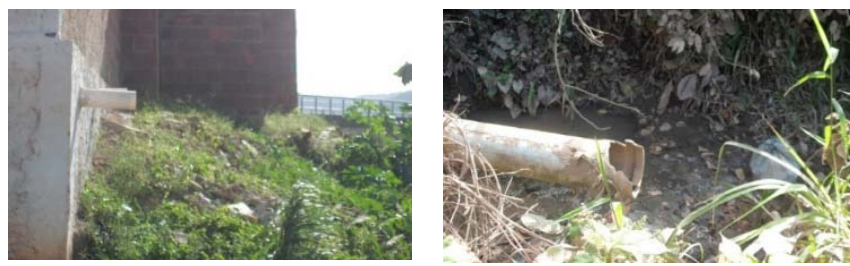

Fonte própria.

Vale ressaltar que este problema de falta de saneamento básico não é um fato isolado desta comunidade, pois, conforme aponta Calvi (2010), menos da metade dos municípios brasileiros possuem coleta seletiva de esgotos.

Grafico 4: Questão 5 - Você percebe algum problema que possa está ocorrendo no rio Mamanguape?

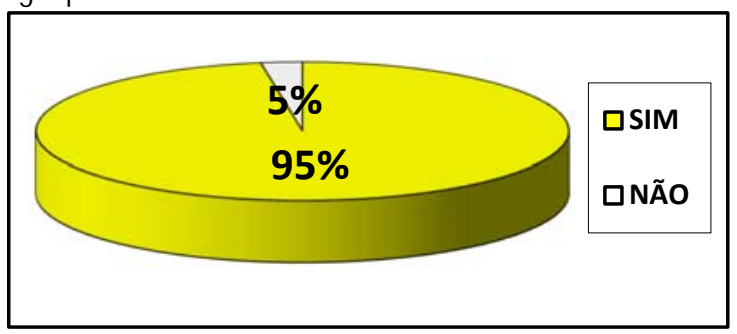

Fonte própria.

De acordo com o gráfico acima, verificamos que 95\% (38 alunos) dos alunos afirmaram nas suas respostas o conhecimento com os problemas que ocorrem com o rio, mas achamos interessante perguntar quais os problemas que eles percebiam em torno do mesmo e as possíveis soluções para esses problemas: Vejamos a tabela 04:

Questão 6: Quais os problemas que afetam o rio Mamanguape e quais as possíveis soluções?

\begin{tabular}{l|l|l}
\hline IDENTIFICAÇÃO & $\begin{array}{l}\text { PROBLEMAS NO RIO } \\
\text { MAMANGUAPE }\end{array}$ & $\begin{array}{l}\text { QUAIS AS POSSÍVEIS } \\
\text { SUGESTÕES } \\
\text { Chover } \\
15 \text { alunos }\end{array}$ \\
& O rio está seco & $\begin{array}{l}\text { Construir uma barragem } \\
\text { Cavar o rio } \\
\text { Parar de tirar areia } \\
\text { Mandar o carro do lixo } \\
12 \text { alunos }\end{array}$ \\
& Tem lixo no rio & $\begin{array}{l}\text { Tirar o lixo } \\
\text { Não jogar o lixo }\end{array}$ \\
\end{tabular}




\begin{tabular}{|c|c|c|}
\hline 7 alunos & Tem esgoto no rio & $\begin{array}{l}\text { Parar de jogar esgoto } \\
\text { Falar na prefeitura } \\
\text { Proibir de jogar esgoto }\end{array}$ \\
\hline 3 alunos & Não tem peixe & $\begin{array}{l}\text { Criar peixe } \\
\text { Parar de jogar lixo } \\
\text { Esperar chover }\end{array}$ \\
\hline 3 alunos & Agua não presta & $\begin{array}{l}\text { Parar de jogar lixo } \\
\text { Esperar chover } \\
\text { Parar de jogar esgoto }\end{array}$ \\
\hline
\end{tabular}

Fonte própria.

De acordo com a tabela exposta acima, percebemos que os problemas apontados pelos alunos são mais visíveis em torno do rio, dentre eles, está a falta de água, sobretudo quando afirmam que "o rio está seco". Porém observamos, dentre as respostas, que as soluções apontadas estão longe das ações da comunidade, a exemplo da "chuva", da criação de uma "barragem" ou ao sugerirem "parar de retirar areia." No entanto, problemas como a inexistência da mata ciliar, o lixo e esgotos que são depositados em suas águas não estão relacionados com os problemas da escassez da água.

Entre os 12 alunos, alguns entenderam que para resolver o problema do lixo bastaria apenas a prefeitura enviar o carro responsável pela sua retirada, mas, não conseguimos identificar entre as respostas as soluções relacionadas a mudança de hábitos e atitudes do ser humano, sendo estas um dos fatores mais importantes para amenizar a degradação ambiental como vimos no Manual de Educação do Consumo Sustentável (2005).

Buscamos ainda constatar a compreensão dos alunos sobre a importância da mata ciliar para a manutenção dos rios, como conhecimento e necessidade de sua conservação para o rio Mamanguape. Vejamos:

Gráfico 5: Questão 7 - Você já ouviu falar em mata ciliar?

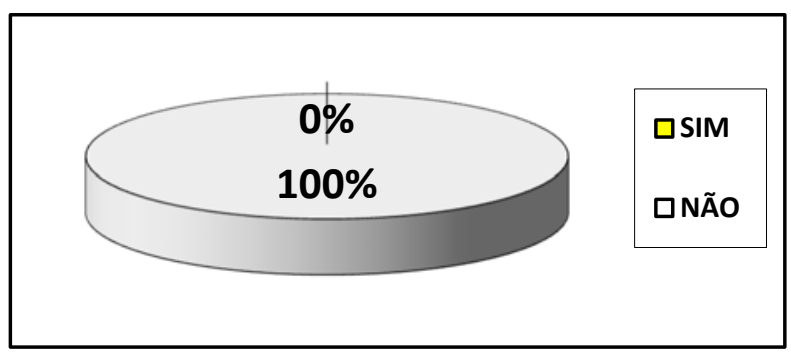

Fonte própria.

Como podemos perceber, os alunos desconhecem sobre um problema seríssimo que acomete o rio, pois diante de suas respostas ficou evidenciado que nenhum aluno das turmas, ouviu falar sobre mata ciliar e nem tão pouco a identificaram como um 
problema, porém, é um fator de suma importância para a preservação do rio, pois evita seu assoreamento.

A partir da imagem abaixo, podemos observar que o córrego é desprovido dessa mata, caracterizando-o como intermitente em consequência de uma falta de vegetação em suas margens, pontuando assim, mais uma situação de degradação ao ecossistema em questão.

Foto 1 - Ausência de mata ciliar nas margens do rio Mamanguape.

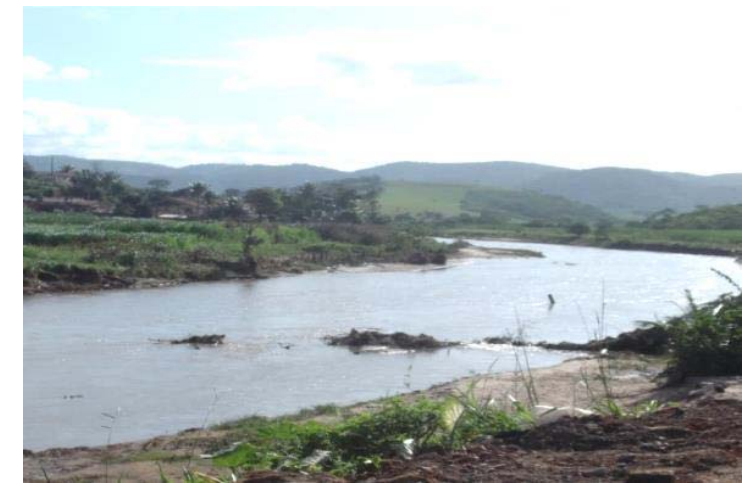

Fonte própria.

Em seguida, perguntamos sobre as aulas que tratam sobre os problemas ambientais e as respostas foram as seguintes:

Gráfico 6: Questão 8 - Você tem aulas sobre Educação Ambiental?

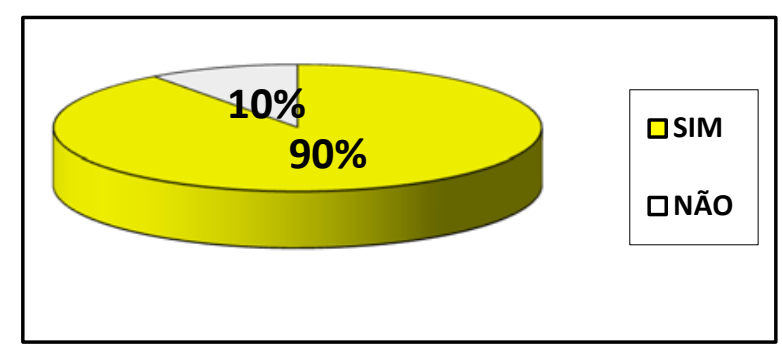

Fonte própria.

Dos participantes, 90\% (36 alunos) disseram ter aulas sobre Educação Ambiental e $10 \%$ (04 alunos) afirmaram que não. Porém, algo nos deixou inquietos, pois as aulas estão acontecendo nas escolas, mas de certa forma, ainda não se tem traduzido em resultados mais curiosos, pois como diz os PCNs, "o convívio escolar será um fator determinante para a aprendizagem de valores e atitudes." (Brasilia 1997 p.37), ou seja, a mudança de hábitos e de atitudes nos indivíduos podem ser fatores determinantes para promover ações de preservação ambiental, onde as aulas sobre a referida 
temática poderá ser um dos caminhos para esta conquista, a partir das atividades, reflexões e discussões oportunizadas pelas mesmas.

Questão 9 - Qual a importância das aulas sobre problemas ambientais?

\begin{tabular}{|c|c|} 
IDENTIFICAÇÃO & RESPOSTA DOS ALUNOS \\
8 alunos & Para aprender \\
5 alunos & Saber da vida no planeta \\
3 alunos & Gostar do meio ambiente \\
9 alunos & Fazer pinturas \\
15 alunos & Desenhar
\end{tabular}

De acordo com a tabela acima, percebemos que as metodologias para 0 ensino da Educação Ambiental, muitas vezes, consistem em pinturas e desenhos, o que fica evidenciado nas respostas da maioria. Durante a exposição dos questionamentos anteriores, percebemos que os problemas ambientais estão muito próximos dos alunos, bem atrás do muro da escola e seria muito interessante se os professores tratassem dos problemas ambientais sem se deter apenas ao "quadro, giz e papel", pois se limitar apenas a estes recursos pode causar uma desconexão entre o que se aprende e o que se vive.

Sendo assim, mediante as respostas dos alunos, percebemos que as aulas sobre Educação Ambiental são realizadas, porém ainda são insuficientes para viabilizar ao aluno 0 entendimento mais abrangente e consciente sobre os problemas ambientais tão próximos de sua realidade. Notamos que ainda existe um distanciamento entre os conteúdos e o cotidiano do alunado, onde os professores não tem conseguido efetivar os objetivos das orientações pedagógicas dentro da sala de aula sobre a temática. Tudo isso poderá se desdobrar em outras investigações que, neste momento, não se constituíram objeto de estudo dessa pesquisa.

Assim, detectar formas de preservação ambiental, que porventura estejam ocorrendo na região, desenvolver o senso crítico e oferecer oportunidade para a discussão de medidas que possam ser tomadas para mudança de atitudes, são alguns dos caminhos norteadores que podem viabilizar ao aluno um entendimento mais amplo de conservação do meio ambiente nas aulas de Educação Ambiental.

\section{5.-Considerações Finais.}

Ao final deste estudo, podemos observar que existem problemas gravíssimos em torno do rio, ficando mais compreensível e urgente para nós a inserção da temática sobre os cuidados com o nosso planeta na sala de aula. Sabemos que as escolas têm oferecido aulas sobre as questões ambientais, mas, que não são suficientes para desenvolver mudanças de hábitos e atitudes nos indivíduos, ações prioritárias para contribuírem com a preservação do Meio Ambiente.

Mesmo assim, são de suma importância que as aulas sobre esta temática estejam focadas em estratégias contextualizadas com a realidade dos alunos, utilizando-se de recursos diversificados que viabilize momentos de reflexão e ação para a sensibilização e construção de novas ideias e aprendizagens, capazes de formar 
cidadãos conscientes e comprometidos com as questões sobre preservação ambiental.

Sendo esse assunto bastante amplo e complexo, sugerimos que seja abordado nos seus diferentes aspectos (científico, social, político, comportamental), sugere-se priorizar: noções sobre captação da água, tratamento e distribuição para o consumo, os hábitos de utilização em casa e na escola adequados às condições locais, a necessidade e as formas de tratamento dos detritos humanos, coleta, destinação e tratamento de esgoto com procedimentos possíveis adequados às condições locais, dentre outros.

Por outro lado, podem-se buscar as contribuições necessárias a partir da Secretaria Municipal de Educação, a fim de propor um envolvimento ainda com as lideranças comunitárias, as Secretarias Municipais de Meio Ambiente e de Saúde, considerando que são órgãos que detém uma participação bastante significativa nessa temática.

\section{6.-Referências.}

Alves, C.A (2007). Educação Ambiental e formação de uma mentalidade ecológica: um estudo sobre a eficácia das ações desenvolvidas no Ensino Fundamental. http://recil.grupolusofona.pt/bitstream/handAcesso em: 21 de set de 2019.

MEC. (2004). Continuada, Alfabetização e Diversidade. Meio Ambiente e Qualidade de Vida na Escola: Construindo Agenda 21 na escola. Ministério da Educação, Revista: M.M.A. Brasília.

PCN. (1997). Parâmetros curriculares nacionais: Meio Ambiente e Saúde / Secretaria de Educação Fundamental. Brasília: MEC/SEF.

Calvi, G. (2010). Água, Meio Ambiente e vida. 3 ed. São Paulo: Global.

Marcatto, C. (2002). Educação Ambiental: conceitos e princípios. Belo Horizonte: FEAM.

Reigota, M. (2001). O que é educação ambiental. Brasiliense: Cortez.

Severino, A. J. (2007). Metodologia do trabalho científico. 23. ed. Ver. e atual. São Paulo: Cortez.

Rosa, A.V. (2001). Abordando as relações entre agricultura e meio ambiente, através da Educação Ambienta. São Paulo: Esalq. 